\title{
Suggestions for strategies when communicating via in-person interpreters: A qualitative study on communication within home care services in Sweden
}

\author{
Elisabeth Björk Brämberg ${ }^{1,2}$, Lars Sandman ${ }^{1}$ \\ 1. School of health sciences, University of Borås, Borås, Sweden. 2. Institute of environmental medicine, Division of \\ intervention and implementation research, Karolinska Institute, Stockholm, Sweden.
}

Correspondence: Elisabeth Björk Brämberg. Address: School of health sciences, University of Borås, SE-501 90 Borås, Sweden. Email: Elisabeth.bjork.bramberg@ki.se

Received: November 10, $2013 \quad$ Accepted: April 24, 2014

Online Published: April 27, 2014

DOI : $10.5430 /$ cns.v2n3p34

URL: http://dx.doi.org/10.5430/cns.v2n3p34

\section{Abstract}

The aim of this study was to explore and suggest strategies for communicating via in-person interpreters, based on experiences of professional home care providers (i.e. nurses and nurse assistants) and social workers. Home care services with its multifaceted emphasis on physical, psychological, social aspects of care and focus on quality of life for the patients presents a challenge for successful interpreted communication as the communication have to cover a wide variety of topics. Previous studies have shown that non-medical issues tend to be less communicated about when using interpreters. The study has an interpretative design, and data were collected in seven focus groups interviews with registered nurses, assistant nurses and social workers in home care services. Data were analysed by means of inductive content analysis. The results reveal suggestions for strategies: making preparations for structure and transparency, creating a flowing conversation on multifaceted topics, forming an understanding of the patient's voice and limiting the information content. This study concludes that the home care providers and social workers need to be prepared for communication via an interpreter about complex phenomena, that communicating information via an interpreter requires preparation prior to the meeting, as well as being an active part in the conversation. Infrequent use of professional interpreters could threaten the possibilities for care providers and social workers to communicate with linguistic diverse patients in an optimal way.

\section{Key words}

Communication, Home care services, Interpretation, Qualitative research

\section{I ntroduction}

The clinical encounter is dependent on accuracy in the communication between the professional care provider (i.e. nurses, nurse assistants and social workers) and the patient. For patients and care providers not sharing a common language, using an interpreter for translation of verbal utterances during the encounter is essential for providing high-quality care and equal access to health care for all individuals ${ }^{[1]}$. However, interpretation of a dialogue between a patient and a care provider is a complex process. When an interpreter is present, the communication and relation between the patient and the caregiver changes from a dyadic into a triadic relationship ${ }^{[2-4]}$. The existing body of knowledge highlights that professional 
interpreters translate with higher quality and covering a wider area of topics compared to bilingual care providers or family members ${ }^{[5-8]}$.

There is a lack of literature on strategies on behalf of the care provider for successfully accomplishing three-way communication ${ }^{[9-12]}$. Rather, studies report on lack of awareness of interpreter models and unrealistic expectations on the interpreter in the clinical encounter ${ }^{[13,14]}$. Generally it is argued that the provider and the interpreter should establish shared goals, professional boundaries and patterns of collaboration ${ }^{[15]}$. This study addresses the problem of using an interpreter within the arena of home care services. Home care services with its multifaceted emphasis on physical, psychological, social aspects of care and focus on quality of life for the patients presents a challenge for successful interpreted communication as the communication have to cover a wide variety of topics. In a comparative, oncology setting study, Butow et al. ${ }^{[16]}$ found that doctors spoke less to patients with immigrant backgrounds compared to native born patients. Immigrant patients were more likely to have summarized information and proportionally less time were spent on cancer-related issues compared to native born patients. Fatahi et al ${ }^{[17]}$ also report that general practitioners experienced that person-related and practical issues such as arrangement of chairs, remote or in-person present interpreter and placing, might negatively influence the encounter when the communication were interpreted.

Some organizational strategies for successful communication are recruitment of high-quality medically trained interpreters to interpreter agencies and co-operation between health care services and interpreter agencies ${ }^{[18]}$. Moreover, to perform high-quality interpretation, the language service needs to be integrated into organisational routines ${ }^{[19]}$. Training health care professionals in working with interpreters has been shown to increase the use of interpreter services as well as maintaining patient-centeredness when the clinical encounter involves an interpreter ${ }^{[20]}$, and the quality of communication during the clinical encounter ${ }^{[21,22]}$.

Few studies highlight the perspective of patients in need of interpreters translating the dialogue between the patient and the care provider. According to Hadziabdic, Heikkila, Albin, and Hjelm ${ }^{[23]}$ patients emphasized the importance of the interpreter being perceived as trained in medical terminology and translation ability. The interpreter is a communication aid and a guide in the health care system in terms of providing information about how the system works. In the consultation, the patient's understanding and trust increased when the interpreter adapted his/her language into the patient's native dialect ${ }^{[23]}$. Wiking et al. ${ }^{[11]}$ explored triangular meetings between patients, interpreters and general practitioners. The findings reveal that $63 \%$ of the patients were satisfied with the consultations. Nevertheless, communication difficulties were reported by $50 \%$ of the patients, despite the use of interpreters in such consultations.

In Sweden, less than a third of the spoken languages have proficiency examination for authorization as interpreter. Approximately $40 \%$ of the interpreters are authorized ${ }^{[17]}$. Clinical encounters interpreted by in-person interpreters have significantly shorter throughput times compared to telephonic interpreters and bilingual care providers ${ }^{[24]}$.

Lack of skilled interpreters and efficient use of limited time can however pose an even greater challenge given the specific challenges of home care services where there is less focus on well restricted medical subject areas and more focus upon complex quality of life issues. Up to date, there is a general lack of research on the use of interpreters within the home care services. This study is part of a larger project where a previous study focused on describing home care providers' and social workers' experiences in communication via in-person interpreters ${ }^{[3}$. In this study we found that the care providers expressed a traditional view on interpretation. The interpreter was supposed to act as a neutral conduit of what the care providers and patients said. At the same time, the interpreter was expected to observe the patient, and when needed, explain medical terms and concepts. Thus, the interpreter was expected to exceed the basic conduit-role. Given these circumstances and views, little is known about care providers' own strategies in achieving a successful communication using professional interpreters. Hence, the aim of this study was to explore and suggest strategies for communicating via in-person interpreters, based on experiences of home care providers and social workers. 


\section{Method}

\subsection{Design}

The study has an interpretative design, focusing on the understanding of persons' different perspectives on their lived realities and its focus is on the participants' experiences of their lifeworld ${ }^{[25]}$.

\subsection{Sampling and participants' characteristics}

The participants were purposively selected. The inclusion criteria were experience from communication via professional in-person interpreters with patients who do not share a common language, within home care services. The exclusion criteria were communication through interpreters with persons using sign language. The first author (EBB) contacted seven managers of home care services by telephone and e-mail, in two cities in the west of Sweden. The managers were briefly informed about the study. When given permission, the first author informed about the study's aim, data collection procedures and that the participation was voluntary, in face-to-face meetings with nurses, assistant nurses and social workers. The managers were present at these meetings. In total, approximately 50 persons were informed about the study and of these 27 participated in seven focus groups interviews performed between September and November 2010. 25 persons declined participation due to no, or limited experience in communicating via in-persons interpreters.

\subsection{Setting}

The selection of data collection scenes was guided by variation in socio-geography. The focus groups took place in two cities in the west of Sweden: a major city with approximately 500000 inhabitants and a smaller town with approximately 100000 inhabitants.

\subsection{Data collection}

Data were collected using focus groups interviews ${ }^{[26,27]}$. It is recommended that power imbalance should be avoided in focus groups ${ }^{[28]}$. Power imbalance might influence group interaction negatively and hindering the participants from talking openly. We strived to avoid such imbalance by planning for focus groups with participants with equivalent educational background, in this case 3-year or more university education (nurses and social workers) or upper secondary education (assistant nurses). When the focus groups were performed it was not possible to arrange the participants as mentioned, due to geographical distance between the participants having equivalent educational backgrounds and willing to participate (see Table 1). Moreover, informal hierarchies might arise as consequences of the participants' age, ethnicity and professional experiences. For example, the participants were all experienced in communicating via interpreters, but to a diverse extent, ranging from a few occasions to comprehensive experiences. However, performing a qualitative data collection implies striving for variation.

The focus groups took place at the participants' workplaces, managed by a moderator (the first author, a PhD nursing researcher, experienced in qualitative interviewing) and a co-moderator present (experienced in nursing research). Both the moderator and the co-moderator were unknown to the participants. The participants and the moderator were seated in a circle facing one another. The co-moderator was seated aside, taking field notes. All focus groups started with the moderator informing about the study's aim and explaining the reason for choosing a focus group methodology; that it is the group's discussion and commenting on one another's utterances that is important, rather than each participant addressing the moderator. Specifically, to avoid the mentioned imbalance, the moderator informed that the participants were presumed having different experiences in communicating via interpreters and were therefore asked to speak openly about their experiences and discuss the other participants' utterances.

The interviews were semi-structured and an interview guide was used. The guide was pilot-tested in the first focus group and after the interview, the participants commented on the questions. A few revisions were made after the interview but they were not of substantial character and thus the first focus group was included in the study. Main topics in the guide 
were related to the use of 1) strategies when communicating via an interpreter, such as strategies for accomplishing a flowing conversation; 2) how to accomplish a relation to the patient despite language barriers; and 3) strategies in case of information loss in the conversation. The initial questions for the main topic were 1) "What strategies do you use when communicating via an interpreter?" 2)" Can you tell me about how you establish a relation to the patient, in the presence of an interpreter?” 3) "If you recognise or suspect information loss during the communication, how do you act?” Each topic and question was thoroughly discussed in the focus group, and when necessary, the moderator asked follow-up questions, for example "Can you please tell us more about this strategy?" or addressed the group "what are your reflections of what XX just told?” The questions in the interview guide were asked in all focus groups. The follow-up questions varied as the groups responded differently. The focus groups lasted between 45 and 70 minutes, were digitally recorded and transcribed verbatim by the first author.

Table 1. Background characteristics of participants

\begin{tabular}{llllllll}
\hline $\begin{array}{l}\text { Focus } \\
\text { group } \\
\text { no. }\end{array}$ & Research site & $\begin{array}{l}\text { No. } \\
\text { Registered } \\
\text { nurses }\end{array}$ & $\begin{array}{l}\text { No. Social } \\
\text { workers }\end{array}$ & $\begin{array}{l}\text { No. } \\
\text { Assistant } \\
\text { nurses }\end{array}$ & $\begin{array}{l}\text { No. } \\
\text { women }\end{array}$ & $\begin{array}{l}\text { No. men } \\
\text { in home care } \\
\text { (years) }\end{array}$ \\
\hline 1 & Major city & 0 & 2 & 1 & 2 & 1 & $5-15$ \\
2 & Major city & 2 & 1 & 1 & 4 & 0 & $1-10$ \\
3 & Small town & 2 & 1 & 1 & 4 & 0 & $2-8$ \\
4 & Major city & 3 & 2 & 0 & 5 & 0 & $8-15$ \\
5 & Small town & 2 & 2 & 0 & 4 & 0 & $3-10$ \\
6 & Small town & 1 & 1 & 1 & 3 & 0 & $2-8$ \\
7 & Major city & 2 & 2 & 0 & 3 & 1 & $3-10$ \\
\hline Total & & 12 & 11 & 4 & 25 & 2 & $1-15$ \\
\hline
\end{tabular}

\subsection{Data analysis}

An inductive content analyse was performed ${ }^{[29]}$. The analysis started with the data transcriptions being read through several times, to obtain a sense of the content. Next, an open coding was applied to the text. The text was re-read, and meanings or sections corresponding to the study's aim were labelled with a code i.e. few words describing the content or different aspects of the content. The open codes along with the meaning or sections from the data were transferred to coding sheets. When transferring the open codes, we sought for similarities and differences. Codes with a similar content where transferred into the same coding sheet. Thereafter, the open codes were explored to find different aspects and the data was classified into sub-categories. The sub-categories were explored by comparing similarities and differences and classified into categories. The sub-categories and categories are derived from the data. The authors independently analysed the data. Discrepancies in the interpretation of data were solved in dialogue between the authors, who continuously discussed the emerging analysis and agreed on the final categories ${ }^{[30]}$. The analysis benefited from the different academic backgrounds of the authors (e.g. caring science and care ethics/philosophy). Care providers (not participating in the study) commented on the latter version of the analysis. The analysis resulted in four categories.

\subsection{Ethical considerations}

The study's design was approved by the Regional Ethics Review Board in Gothenburg (D-nr 432-10). Before the focus group interviews, the participants were informed that their participation was voluntary and that they had the right to withdraw at any time without stating any reason for doing so. Written informed consent was obtained from all participants. 


\section{Results}

The results are presented in the categories "Making preparations for structure and transparency", "Creating a flowing conversation on multifaceted topics", "Forming an understanding of the patient's voice" and "Limiting the information content”.

\subsection{Making preparations for structure and transparency}

The participants in the focus groups told that they needed to make certain preparations before a consultation, in order to create a well-structured and transparent interpretation session given the multitude and complexity of issues to be dealt with in the home-care context.

The focus groups revealed that before the meetings it was essential to prepare an agenda with questions as well as the order in which they should be asked, whilst also keeping an open mind if the order of the conversation came to be altered.

In order to set the scene, the participants in the focus groups explained that they needed to prepare the patient and family members for the different roles and functions of the participants, usually the interpreter and the care provider. The professional interpreter introduced her/himself, explained her/his function as translator of the conversation and informed the others about confidentiality protections. The care provider explained her/his role and duties during the meeting.

I think the roles, or different roles, who you are... I attended a meeting with one of the social workers and an interpreter. It was a problem for the patient, which roles did we have, all of us attending the meeting? It was a difficult situation for the patient. Family members were present, other care providers, the social worker, the interpreter and myself, as support for the social worker. And, it was hard to know who was going to talk, who was going to respond. I guess it was very difficult for the patient to know (Focus group 6).

\subsection{Creating a flowing conversation on multifaceted topics}

The participants used several strategies to create a flowing conversation between the care provider, the patient and the interpreter and to allow the interpreter to translate as verbatim as possible. The strategies were seen to be important for revealing the conversations' multifaceted topics as well as non-medical issues related to the patient's quality of life, and practical issues related to home care services.

The number of participants should be reduced. If parallel conversations arose, for example, between care providers or between the patient and family members, the order of the conversation became difficult to follow. Consequently, it became difficult for the interpreter to sort out the speakers and complete the translation successfully. In order to block out or interrupt the parallel conversations, the interpreter was placed beside or behind the patient and the other participants usually sat opposite the patient and had her/him in focus and therefore being able to maintain eye contact, when asking questions and listening to the interpreter's translation. The strategy was used to emphasize that the conversation involved the patient, the care provider and the interpreter, and hinted to the other participants that they should be quiet.

Speak to the one who's being interpreted, speak directly to and have eye contact with the patient. Don't turn to the interpreter and talk about the patient. It's not good manners (another participant agrees). I think that's the most important thing to do (The other participants agree). It usually makes the conversation flow between the care provider, the patient and interpreter, because it shows respect. Shortly, the family members or other care providers understand the order of the conversation. I want the answers from the patient, I look at you and talk to you (Focus group 7).

It's about the form. I sit down with the patient opposite me, the interpreter is seated beside the patient and myself. When I say something it's interpreted and then I have to listen to the translation. It's, yes, it becomes a flow. Another participant: Yes, it becomes like a flow between the patient, the interpreter and myself (Focus group 2). 
The feeling of immediacy between the participant and the patient was supposed to be emphasized by the interpreters' use of "first person". The interpreter usually spoke in the first person, which created the feeling of a dialogue between the care provider and the patient, with the interpreter as an invisible party. This form of conversation was intended to give the impression that the interpreter's translation was an objective, verbatim translation of the patient's voice.

The participants reflected on their own use of words, pauses and language. The way they expressed themselves was a meaningful facilitation of a successful translation. For example, they recommended talking in short sentences and then waiting for the interpreter's translation. The participants also reflected on which words to use and were prepared to explain and simplify concepts in order to create a well-defined conversation.

I think what you said was a key word (nods at another participant). You have to be clear when talking. Be concise, informative and distinct, and you might avoid misunderstandings. I know misunderstandings arise quite easily in these conversations (Focus group 4).

A skilled interpreter was expected to interrupt the care provider or the patient if they talked too much or too long without pausing, as well as to refer to not being able to translate everything being said at the same time.

By talking in a clear manner, simplifying and explaining concepts, the participants wanted the patient to understand the information and what it meant to her/him.

\subsection{Forming an understanding of the patient's voice}

In order to form an opinion of the quality of the translation and what the patient had told and the interpreter had translated, the participants tried to listen attentively to the interpreter's words. If the statement from the patient was different from what was expected, it could be a sign that the patient had not received all the information. When these situations occurred, the participants tried to reformulate their information and questions to the patient.

By means of the answer you can hear that your message, or what you've said, has reached the patient. And sometimes the question might be misunderstood and you have to reformulate it. Another participant: Yes, it's difficult to be sure whether what I've said reaches the patient, because you don't understand what the interpreter says; I never get proof that we're talking about the same thing or that the translation's correct. If the answer seems strange, you get proof that, okay, this answer seemed odd, but sometimes it might be very difficult to know if the message gets through (Focus group 3).

In order to minimize the problems in the quote, before a new topic of conversation was introduced, or before the meeting had ended, the participants tried to summarize what had been said and asked the patient whether the summary was correct.

\subsection{Limiting the information content}

In the multidimensional and complex information context of home care, care providers saw the need of limiting the information content to be dealt with in a single interpretation session.

According to the participants, the use of professional interpreters was too infrequent to match the need of home care services. This resulted in a great deal of information being communicated to the patient on one occasion, i.e., when an interpreter was present. As a consequence, these meetings could sometimes take on a different focus than that was planned. The participants spoke of patients who had been in the hospital for weeks without being offered communication via a professional interpreter. When an interpreter was at last commissioned, in connection with discharge-planning conferences before being transferred to home care, the patient and sometimes family members had a large number of questions about medical issues such as illness and treatment, and these related to the in-hospital care. Issues related to how to handle the situation when the patient got home became secondary. It thus occurred quite often that meetings became confusing and disordered and misunderstandings arose. 
I've attended a couple of discharge-planning conferences that were confusing and disordered in terms of the communication. There have been misunderstandings from the hospital. The care providers at the hospital have given poor information about the patient' s condition and the discharge process from the hospital. And then you have to take all the questions into consideration at a discharge-planning conference. There are questions directed at the physician, or at the nurses, at the hospital. The interpreter, the patient and sometimes the family members discuss the questions, because they're frustrated; sometimes the patient and family members have not received information at all (Focus group 2).

The participants felt that this way of communicating information via an interpreter was against the generally accepted way of informing patients without the need of interpretation. Limiting the information content meant more space and time for the patient and family members to reflect over the information and ask questions.

At the meetings we have to inform quite a lot; it doesn't matter whether you're Swedish, Norwegian or who you are. You don't remember all the information you receive at a meeting. And you know this, even if you as a care provider have a lot of information and you think you've been clear, you think the interpreter has done a correct translation. It might be that the patient doesn't remember everything (Focus group 1).

In order to be able to limit the information content per session the care providers drew the conclusion that a more frequent use of interpreters is needed.

\section{Discussion}

The results reveal some suggestions for strategies when communicating via in-person interpreters as experienced by professional home care providers and social workers. In summary, making preparations for structure and transparency meant preparing an agenda, and keeping in mind that the conversation's topics could be altered. Creating a flowing conversation on multifaceted topics intended reducing the number of participants, hindering that parallel conversations arose and strengthen the feeling of immediacy, i.e., that the conversation was between the care provider and the patient. The use of words, pauses and language was exemplified by talking in short sentences, having pauses and being prepared to explain words and concepts. Forming an understanding of the patient's voice was made by listening attentively to the interpreter. By means of the answer, the care providers could form their opinions whether the patient had received the information or if misunderstandings had arose. Before introducing a new topic, the information could be summarized. Limiting the information was seen as necessary in order for the patient to get a grasp of the content. The participants concluded that an increased use of interpreters within home care services is needed.

Previous research on strategies for interpreted communication mainly relate to the access to professional interpreters ${ }^{\text {[31] }}$, use of relatives or bilingual care providers as interpreters ${ }^{[8]}$ or underutilisation of trained interpreters ${ }^{[32]}$. Other studies report organizational strategies such as recruitment of medically trained interpreters, co-operation between interpreter agencies and health care services and interpreter service integrated in the health care organization ${ }^{[18,19]}$ or training health care professionals in interpreted communication ${ }^{[20]}$. In the present study, we did not estimate the use of professional interpreters or ad hoc interpreters. However, the findings reveal a call for more use of professional interpreters in the home care setting. Our findings show strategies for how to prepare and perform the three-way communication, from the experiences of home care providers. The findings thus differ from previous studies that have an organizational perspective or highlight the general lack of access to professional interpreters. One of the strategies in the present study is to make preparations for structure and transparency, for example by prepare the patient and family members of the different roles and functions of the care provider and interpreter. This is partly confirmed by Hsieh et al. ${ }^{[15]}$ which emphasizes the need for establishment of shared goals and how to collaborate between the care provider and interpreter. We argue that the patient and if present, family members, are to be invited into the collaboration. It is moreover essential that the interpreter and care provider have no agenda of their own, but rather see their role as that of being facilitators to enable proper care for the patient, as confirmed by previous studies ${ }^{[23,33]}$. 
Furthermore, our study shows that participants experienced the information content being limited during the conversation. This is in line with previous studies ${ }^{[8,16]}$ showing that non-medical issues tend to be less communicated about when using interpreters. We did not ask the participants about if the non-medical issues were less communicated compared to medical issues, because home care service is a multifaceted arena with the complexity of patient's needs, quality of life, treatment and so on. During the focus groups the participants compared the interpreted communication with non-interpreted. The findings reveal that the participants experienced the communication in general was limited.

At the same time as the participants express important suggestions for strategies, valuable for the use of interpreters within home care services with its complex information exchange necessary to provide good care, we also need to critically discuss the fact that they express a traditional view of interpreter use - i.e., the two-way dialogue. It is essential for the participants in the study when imitating a two-way dialogue to give the patient the impression that $\mathrm{s} / \mathrm{he}$ is the focus of the professional's attention and hence that the interpreter is more or less “invisible". However, the interpreter did not appear to be as invisible as the participants implied s/he was and in an earlier study in the same context the interpreter was expected to explain medical concepts etc. to the patient (even if not done by the care provider) ${ }^{[3]}$.

However, since there are problems involved with trying to imitate a two-way dialogue when it is in fact a three-way communication $^{[34,35]}$, we need to discuss whether it is possible to have the patient in focus even within the framework of a three-way dialogue. Comparisons can be made with the way care providers relate to patients when a family member is present, and when the parties share a common language. It is possible to keep the patient in focus, in such a three-way dialogue, even when the family member is involved in the communication. This is dependent on aspects such as which person the care provider mainly turns to, seek eye contact with, etc. It is important to avoid always turning to the family member, even in cases in which s/he is the more communicative one.

A further important aspect of the two-way dialogue ideology is the aim for verbatim translation. This is supposed to achieve an information exchange in which no information is lost on the way ${ }^{[21]}$. The care providers in the present study, however, obviously limited the information content as well as lost information during the communication, for example, concerning the patient's reactions, and there was information that needs to be further explained to the patient. If we look at the communication situation from a perspective of it being an information complex, consisting of verbal and non-verbal information that should be communicated between the patient and the care provider, this could provide us with reasons to abandon the aim for verbatim translation ${ }^{[2,13]}$.

\section{Methodological considerations}

This small-scale study addresses the problem of interpreted communication and strategies in achieving a successful communication using interpreters. The study is limited to a context of home care services in Sweden.

Strength of the study is the authors' different theoretical perspectives and scientific backgrounds ${ }^{[36,37]}$.

Formal as well as informal hierarchies in the groups might constitute a risk for biased information. As recommended by Kitzinger ${ }^{[28]}$ we strived for, but could not achieve, homogenous focus groups, due to geographical location and working hours. To some extent it might be possible to avoid imbalance in the groups, with regard to gender, educational background et cetera. However, the participants' individual experiences of the topic of interest will most likely differ, even if there were no or very limited differences in for example educational background. In our study, the participants told about situations of communicating via interpreters, which referred to their diverse professional experiences. In fact, their different experiences facilitated the discussion. A negative side-effect of the interaction in the groups was the implied norms within a profession. In some of the groups, the more outspoken participants opened up the discussion, and paved the way for the more modest participators. Different methods for data collection, such as observation of clinical encounters or recording of clinical encounters, might have provided additional information to this study. However, we argue that the 
participants in the focus groups provided rich and interesting data, which highlight different aspects of their experiences on communicating via in-person interpreters.

By means of quotations in the findings, the discussions and interactions between the participants are illustrated. Moreover, the quotations illustrate how the categories are connected to the data and representing all focus groups in the study, and therefore strengthens the study's validity. The quotations might contribute to an understanding of how the interaction was like in the focus groups ${ }^{[26]}$.

\section{Conclusions}

In order to provide successful three-way communication in situations using an interpreter within home care services, the home care providers and social workers need to be prepared for communication via an interpreter about complex phenomena. Communicating information via an interpreter requires preparation prior to the meeting, as well as being an active part in the conversation. Infrequent use of professional interpreters could threaten the possibilities for care providers and social workers to communicate with linguistic diverse patients in an optimal way. In a three-way dialogue it is essential to give the patient the impression that s/he is in the focus of the care provider's attention. We need to develop knowledge about if and how interpreters should translate the patient's non-verbal expressions as well as the verbal content of what s/he says.

\section{References}

[1] Hendriks A. Ethnic and cultural diversity: challenges and opportunities for health law. European journal of health law. 2008; 15: 285-295. PMid:19024865 http://dx.doi.org/10.1163/157180908X338232

[2] Angelelli CV. Medical interpreting and cross-cultural communication. New York: Cambridge university press; 2004. http://dx.doi.org/10.1017/CBO9780511486616

[3] Björk Brämberg E, Sandman L. Communication through in-person interpreters: a qualitative study of home care providers’ and social workers’ views. Journal of Clinical Nursing. 2013; 22(1-2): 159-167. PMid:23170919 http://dx.doi.org/10.1111/j.1365-2702.2012.04312.x

[4] Rosenberg E, Leanza Y, Seller R. Doctor-patient communication in primary care with an interpreter: physician perceptions of professional and family interpreters. Patient education \& counseling. 2007; 67: 286-292. PMid:17448622 http://dx.doi.org/10.1016/j.pec.2007.03.011

[5] Elderkin-Thompson V, Silver RC, Waitzkin H. When nurses double as interpreters: A study of Spanish-speaking patients in a US primary care setting. Social science \& medicine. 2001; 52(9): 1343-1358. http://dx.doi.org/10.1016/S0277-9536(00)00234-3

[6] Flores G, Abreu, M, Barone, CP, Bachur R, Lin H. Errors of medical interpretation and their potential clinical consequences: a comparison of professional versus ad hos versus no interpreter. Annals of Emergency Medicine. 2012; Nov; 60(5): 545-53. PMid:22424655 http://dx.doi.org/10.1016/j.annemergmed.2012.01.025

[7] Green AR, Ngo Metzer Q, Legedza ATR, Masagli MP, Philips, RS, Iezzoni, LI. Interpreter services, language concordance and health care quality. Experiences of Asian Americans with limited English profiency. Journal of general internal medicine. 2005; 20(11): 1050-1056. PMid:16307633 http://dx.doi.org/10.1111/j.1525-1497.2005.0223.x

[8] Rosenberg E, Richard C, Lussier MT, Shuldiner T. The content of talk about health conditions and medicatons during appointments involving interpreters. Fam Pract. 2011; 28(3): 17-22. PMid:21088097 http://dx.doi.org/10.1093/fampra/cmq094

[9] Fatahi N, Mattsson B, Hasanpoor J, Skott C. Interpreters' experiences of general practitioner - patient encounters. Scandinavian journal of caring sciences. 2005; 23: 159-163.

[10] Hsieh E. "I am not a robot!" Interpreters' views of their roles in health care settings. Qualitative health research. 2008; 18(10), 1367-1383. PMid:18832768 http://dx.doi.org/10.1177/1049732308323840

[11] Wiking E, Saleh-Stattin N, Johansson SE, Sundqvist J. A description of some aspects of the triangualar meeting between immigrant patients, their interpreters and GPs in primary health care in Stockholm, Sweden. Family practice. 2009; 26(5): 377-383. PMid:19713217 http://dx.doi.org/10.1093/fampra/cmp052 
[12] Wiking E, Sundquist J, Saleh-Stattin N. Consultations between Immigrant Patients, Their Interpreters, and Their General Practitioners: Are They Real Meetings or Just Encounters? A Qualitative Study in Primary Health Care. Int J Family Med. 2013; Article ID 794937, 10 pages.

[13] Hsieh E. Understanding medical interpreters: reconceptualizing bilingual health communication. Health Communication. 2006b; 20(2): 177-186. PMid:16965255 http://dx.doi.org/10.1207/s15327027hc2002_9

[14] Hudelson P. Improving patient-provider communication: insights from interpreters. Family practice. 2005; 22: 311-316. PMid:15805131 http://dx.doi.org/10.1093/fampra/cmi015

[15] Hsieh E, Hong S, Ju H. Not all are desired: providers' views on interpreters' emotional support for patients. Patient Education and Counseling. 2010; 81(2): 192-197. PMid:20430564 http://dx.doi.org/10.1016/j.pec.2010.04.004

[16] Butow PN, Goldstein D, Bell ML, Sze M, Aldridge L, Abdo S, Eisenbruch M. Interpretation in consultations with immigrant patients with cancer: how accurate is it? Journal of Clinical Oncology. 2011; 29(20): 2801-2807. PMid:21670462 http://dx.doi.org/10.1200/JCO.2010.34.3335

[17] Fatahi N, Hellstrom M, Skott C, Mattsson B. General practitioners' views on consultations with interpreters: a triad situation with complex issues. Scand J Prim Health Care. 2008; 26(1): 40-45. PMid:18297562 http://dx.doi.org/10.1080/02813430701877633

[18] Hadziabdic E, Heikkilä K, Albin B, Hjelm K. Problems and consequences in the use of professional interpreters: qualitative analysis of incidents from primary healthcare. Nursing Inquiry. 2011; 18(3): 253-261. PMid:21790876 http://dx.doi.org/10.1111/j.1440-1800.2011.00542.x

[19] Greenhalgh T, Voisey C, Robb N. Interpreted consultations as 'business as usual'? An analysis of organisational routines in general practices. Sociology of Health and Illness. 2007; 29(6): 931-954. PMid:17986023 http://dx.doi.org/10.1111/j.1467-9566.2007.01047.x

[20] Fung CC, Lagha RR, Henderson P, Gomez AG. Working with interpreters: how student behavior affects quality of patient interaction when using interpreters. Medical Educucation Online. 2010; 15: 5151. PMid:20532030 http://dx.doi.org/10.3402/meo.v15i0.5151

[21] Flores G, Laws MB, Mayo SJ, Zuckerman B, Abreu M, Medina L, Hardt EJ. Errors in medical interpretation and their potential clinical consequences in pediatric encounters. Pediatrics. 2003; 111(1): 6-14. PMid:12509547 http://dx.doi.org/10.1542/peds.111.1.6

[22] Thompson DA, Hernandez RG, Cowden JD, Sisson SD, Moon M. Caring for Patients With Limited English Proficiency: Are Residents Prepared to Use Medical Interpreters? Acad Med. 2013; 88(10): 1485-1492. PMid:23969358 http://dx.doi.org/10.1097/ACM.0b013e3182a3479d

[23] Hadziabdic E, Heikkila K, Albin B, Hjelm K. Migrants' perceptions of using interpreters in health care. Int Nurs Rev. 2009; 56(4): 461-469. PMid:19930075 http://dx.doi.org/10.1111/j.1466-7657.2009.00738.x

[24] Grover A, Deakyne S, Bajaj L, Roosevelt GE. Comparison of throughput times for limited English proficiency patient visits in the emergency department between different interpreter modalities. Journal of immigrant and minority health. 2012; 14(4): 602-607. PMid:21947693 http://dx.doi.org/10.1007/s10903-011-9532-z

[25] Dahlberg K, Dahlberg H, Nyström M. Reflective Lifeworld Research. Lund: Studentlitteratur; 2008.

[26] Morgan DL. Reconsidering the role of interaction in analyzing and reporting focus groups. Qualitative health research. 2010; 20(5): 718-722. PMid:20406996 http://dx.doi.org/10.1177/1049732310364627

[27] Webb C, Kevern J. Focus groups as a research method: a critique of some aspects of their use in nursing research. Journal of Advanced Nursing. 2001; 33(6): 798-805. PMid:11298218 http://dx.doi.org/10.1046/j.1365-2648.2001.01720.x

[28] Kitzinger J. Introducing focus groups. British Medical Journal. 1995; 311: 299-302. http://dx.doi.org/10.1136/bmj.311.7000.299

[29] Elo S, Kyngäs H. The qualitative content analysis process. Journal of Advanced Nursing. 2008; 62(1): 107-115. PMid:18352969 http://dx.doi.org/10.1111/j.1365-2648.2007.04569.x

[30] Bradley EH, Curry LA, Devers KJ. Qualitative data analysis for health services research: developing taxonomy, themes, and theory. Health Serv Res. 2007; 42(4): 1758-1772. PMid:17286625 http://dx.doi.org/10.1111/j.1475-6773.2006.00684.x

[31] Bischoff A, Hudelson P. Access to healthcare interpreter services: where are we and where do we need to go? Int J Environ Res Public Health. 2010; 7(7): 2838-2844. PMid:20717543 http://dx.doi.org/10.3390/ijerph7072838

[32] Seers K, Cook L, Abel G, Schluter P, Bridgford P. Is it time to talk? Interpreter services use in general practice within Canterbury. J Prim Health Care. 2013; 5(2): 129-137. PMid:23748394

[33] Price EL, Pérez-Stable EJ, Nickleach D, López M, Karliner LS. Interpreter perspectives of in-person, telephonic, and videoconferencing medical interpretation in clinical ecounters. Patient Education and Counseling. 2012; May; 87(2): 226-32. PMid:21930360 http://dx.doi.org/10.1016/j.pec.2011.08.006 
[34] Dysart-Gale D. Clinicians and medical interpreters. Negotiating culturally appropriate care for patients with limited English ability. Fam community health. 2007; 30(3): 237-246. PMid:17563485 http://dx.doi.org/10.1097/01.FCH.0000277766.62408.96

[35] Hsieh E. Conflicts in how interpreters manage their roles in provider-patient interactions. Social Science \& Medicine. 2006; 62(3): 721-730. PMid:16046038 http://dx.doi.org/10.1016/j.socscimed.2005.06.029

[36] Denzin KN, Lincoln YS. The sage handbook of qualitative research. Thousand Oaks, Calif: SAGE Publications Inc; 2011.

[37] Padgett DK. Qualitative and mixed methods in social work knowledge development. Social Work. 2009; 54(2): $101-105$. http://dx.doi.org/10.1093/sw/54.2.101 